\title{
Measurement of primordial radionuclides in soils and building materials from Mizoram, India
}

\author{
L.Z. Chhangte ${ }^{1}$, Hmingchungnunga ${ }^{1}$, Vanramlawma $^{1}$, P.C. Rohmingliana ${ }^{2}$, B.K. Sahoo ${ }^{3}$, B.K. \\ Sapra $^{3}$, B. Zoliana ${ }^{2 *}$, Rosangliana ${ }^{2}$, Z. Pachuau ${ }^{1}$ \\ ${ }^{1}$ Department of Physics, Mizoram University, Tanhril 796004, Mizoram, India \\ ${ }^{2}$ Department of Physics, Government Zirtiri Residential Science College, Aizawl 796007, Mizoram, India \\ ${ }^{3}$ Radiological Physics and Advisory Division, Bhabha Atomic Research Centre, Mumbai 400085, India \\ *Corresponding author: bzoliana@gmail.com
}

\begin{abstract}
Humans are constantly exposed to radiations, of which majority (87\%) is from natural sources and a fraction $(\mathbf{1 3 \% )}$ is from man-made. Construction materials can contribute to natural background radiation in two ways, namely emission of gamma radiation, from primordial radionuclides like uranium, thorium and potassium and their decay products (external dose); and exhalation of radon (internal dose). The nature of soil largely determines the degree of gamma radiation. Measurement of natural radioactivity in soil and building materials from Siaha and Lawngtlai districts in Mizoram was carried out using 5"X 4" Nal (TI) detector. Soil samples were collected from 25 different sites and five different commonly used building materials in the study area are also analysed. The activity concentrations were measured for three principal primordial radionuclides namely, ${ }^{238} \mathrm{U},{ }^{232} \mathrm{Th}$ and ${ }^{40} \mathrm{~K}$. The average activity concentration of soil samples was found to be 33.47 Bq/kg for ${ }^{238} \mathrm{U}, 67.00 \mathrm{~Bq} / \mathrm{kg}$ for ${ }^{232} \mathrm{Th}$ nuclides and $942.25 \mathrm{~Bq} / \mathrm{kg}$ for ${ }^{40} \mathrm{~K}$ nuclides. The average activity concentration of ${ }^{238} \mathrm{U} \&{ }^{232} \mathrm{Th}$ are found to be highest in Glazed tiles and that of ${ }^{40} \mathrm{~K}$ is found to be highest in bamboo.
\end{abstract}

Keywords: Radionuclides, activity concentration, Nal (TI) detector, soil, gamma energy.

\section{INTRODUCTION}

Of all the radiation dose received by human being, about $87 \%$ is due to natural radiation sources and the remaining $13 \%$ by anthropogenic radiation (Kannan et al., 2002). The global average natural radiation dose to humans is about $0.3-1.0 \mathrm{mSv} /$ year which is four times higher than the global average of artificial radiation exposure (UNSCEAR, 2008). Since most of the residents use to spend most of the time indoors, the knowledge of the radioactivity in soil and building materials is important and helps to the study of population exposure to radiations. The building materials may contribute to exposure of human beings to natural background radiation in two ways - emission of gamma radiation, from primordial radionuclides like uranium, thorium and potassium and their decay products (external dose); exhalation of radon (internal dose). The intensity of gamma-radiation de- pends on soil radioactivity and physical features of the surface soil and their relationship to the geological structure of the study area (Karahan and Bayulken, 2000; Degerlier et al., 2008). Since the distribution of the said primordial radionuclides is not uniform, the knowledge of their concentration in soil, rocks and building materials play an important role in radiation protection and measurement (Rani and Singh, 2005).

In this work the estimation of ${ }^{238} \mathrm{U},{ }^{232} \mathrm{Th}$ and ${ }^{40} \mathrm{~K}$ contents in the soil and commonly used building materials in the study area were therefore carried out using a lowlevel gamma ray spectrometer using $\mathrm{Nal}(\mathrm{TI})$ detector. The geographical locations of the study area are Siaha and Lawngtlai districts of Mizoram, India within Latitude - $22^{\circ} 29^{\prime} 28.3^{\prime \prime}$ to $22^{\circ} 36^{\prime} 59.4^{\prime \prime}$ and Longitude $92^{\circ} 59^{\prime} 14.3^{\prime \prime}$ to $92^{\circ} 52^{\prime} 22.0^{\prime \prime}$ with altitude $1866 \pm 10 \mathrm{ft}$ to $3807 \pm 10 \mathrm{ft}$ from the sea level. 


\section{MATERIALS AND MethodS}

\section{Sampling}

25 soil samples and 5 commonly used building materials ( 2 each from the two districts) were collected from the study area. Since the density of sample matrix and its geometry affects the attenuation factor for gamma rays, the samples were crushed to powder and then sieved to minimum size as possible. In order to achieved secular equilibrium between primordial radionuclides and their daughter products, the samples were kept sealed and undisturbed for one month, in a plastic container having the same geometry as the standard sources.

\section{Measurement of radioactivity}

Measurement of radioactive contents of the samples were carried out using $5^{\prime \prime} \times 4$ " Nal (TI) detector coupled with a GSPEC-SA (version $2.5 \mathrm{X}$ ), which is a PC-based multi-channel analyzer. The concentration of ${ }^{238} \mathrm{U}$ were determined using a photo peak of $295 \mathrm{keV}$ (19\%) from ${ }^{214} \mathrm{~Pb}$. ${ }^{232} \mathrm{Th}$ concentration were determined using a photo peak of $167 \mathrm{keV}(0.1 \%)$ from ${ }^{228} \mathrm{Th} .{ }^{40} \mathrm{~K}$ concentration were determined from its $1460 \mathrm{keV}$ (11\%) photo peak.

For efficiency calibration, the IAEA standard samples with known activity were counted for 10,800 seconds. The efficiency was obtained from the particular gamma energy peak of the above radionuclides using the following formula:

$$
\eta(\%)=\frac{\text { Area } / s}{d p s} \times \frac{100}{A \%} \times 100
$$

where $\eta \%$ = Percentage efficiency

Area $/ \mathrm{s}=$ Net peak area (background subtracted) per second

$d p s=$ Source strength in disintegration per second

$A \%=$ Gamma ray abundance factor.

Energy calibration was performed before measurement of radioactive content of the samples. A threepoint energy calibration is carried out using two standard sources, ${ }^{137} \mathrm{Cs}$ (661.62 keV) and ${ }^{60} \mathrm{Co}(1173.24 \mathrm{keV}$ and $1332.46 \mathrm{keV}$ ) (ISO 18589-3:2007(E)).

To arrive at the net radioactivity $(\mathrm{Bq})$ of a particular radionuclide in the samples, counting was done for 50,000 seconds. The activity of particular radionuclides was calculated using the formula

$$
\operatorname{Activity}(\mathrm{Bq} / \mathrm{kg})=\frac{N}{T} \times \frac{100}{\gamma \%} \times \frac{100}{\eta \%} \times \frac{1}{W}
$$

where $W=$ Weight of the sample.

$N=$ Background subtracted net peak area counted in $T$ second.

$\gamma \%=$ Abundance of gamma ray under consideration.

$\eta \%=$ Previously obtained percentage efficiency of the standard source.

\section{RESULTS}

Table 1 and Figure 1 shows the result of measurement of natural radioactivity concentration of principal primordial radionuclides of the soil samples. The activity concentration of ${ }^{238} \mathrm{U}$ range from $19.32 \mathrm{~Bq} / \mathrm{kg}$ to 47.70 $\mathrm{Bq} / \mathrm{kg}$ with the average value of $33.47 \mathrm{~Bq} / \mathrm{kg}, \mathrm{GM}$ of $32.11 \mathrm{~Bq} / \mathrm{kg}$, SD of 9.54 and GSD of 1.34 . The activity concentration of ${ }^{232} \mathrm{Th}$ range from $43.63 \mathrm{~Bq} / \mathrm{kg}$ to 85.61 $\mathrm{Bq} / \mathrm{kg}$ with the average value of $67.00 \mathrm{~Bq} / \mathrm{kg}, \mathrm{GM}$ of $66.32 \mathrm{~Bq} / \mathrm{kg}$, SD of 9.62 and GSD of 1.16 . The activity concentration of ${ }^{40} \mathrm{~K}$ range from $686.58 \mathrm{~Bq} / \mathrm{kg}$ to 1150.81 $\mathrm{Bq} / \mathrm{kg}$ with the average value of $942.25 \mathrm{~Bq} / \mathrm{kg}, \mathrm{GM}$ of $932.29 \mathrm{~Bq} / \mathrm{kg}$, SD of 135.74 and GSD of 1.15.

The radioactive content of some commonly used building materials, namely, asbestos, glazed tiles, bricks, bamboo and wood are also analysed. Table 2 and Figure 2 show the radioactivity content in different types of building materials in $\mathrm{Bq} / \mathrm{kg}$. Asbestos, glazed tiles and bricks contain regular level of the primordial radionuclides, some other materials like bamboo and wood contain only ${ }^{40} \mathrm{~K}$. Thus, the average activity of ${ }^{238} \mathrm{U},{ }^{232} \mathrm{Th}$ and ${ }^{40} \mathrm{~K}$ in commonly used building material in the study area range from 22.22-29.1 Bq/kg, 59.23-144.95 Bq/kg and $436.82-814.18 \mathrm{~Bq} / \mathrm{kg}$ respectively.

\section{DISCUSSION}

The global average value of activity of ${ }^{238} \mathrm{U}$ range from $16-110 \mathrm{~Bq} / \mathrm{kg}$ with the average value of $35 \mathrm{~Bq} / \mathrm{kg}$, global average value of activity of ${ }^{232} \mathrm{Th}$ range from $11-64 \mathrm{~Bq} / \mathrm{kg}$ with the average value of $30 \mathrm{~Bq} / \mathrm{kg}$ and global average value of activity of ${ }^{40} \mathrm{~K}$ range from $140-850 \mathrm{~Bq} / \mathrm{kg}$ with the average value of $400 \mathrm{~Bq} / \mathrm{kg}$ (UNSCEAR, 2000). Our result of the average activity of ${ }^{238} \mathrm{U}$ is lower than that of global average and while the activity of ${ }^{232} \mathrm{Th}$ is a higher than that of the global average. But our result of the average ${ }^{40} \mathrm{~K}$ activity is way above the global average.

Authors like Haquin (2008) and SC Lee et al., (2001) report presence of small amount of ${ }^{226} \mathrm{Ra} /{ }^{238} \mathrm{U}$ and absence of ${ }^{232} \mathrm{Th}$ in wood samples. However, the presence or absence of primordial radionuclides in the bamboo samples has not been recorded to compare with our result.

The average value of activity of ${ }^{238} \mathrm{U}$ is found to be comparable to the global average while the activity of ${ }^{232} \mathrm{Th}$ and ${ }^{40} \mathrm{~K}$ is found to be much more than the global average. The natural radioactivity content of some of the building materials like asbestos, glazed tiles, bricks, bam- 


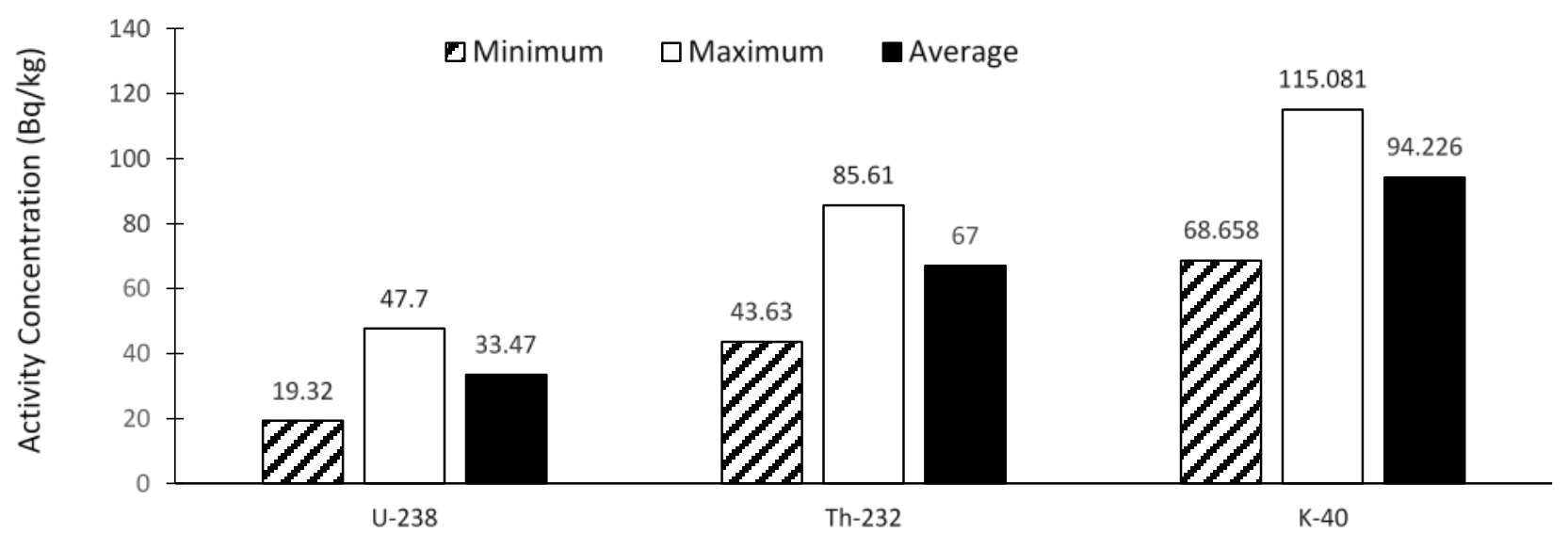

Figure 1: Activity concentration of ${ }^{238} \mathrm{U},{ }^{232} \mathrm{Th} \&^{40} \mathrm{~K}$ in soil samples. (The activity concentration of ${ }^{40} \mathrm{Kis}$ diminished ten times for the sake of convenience for viewing.)

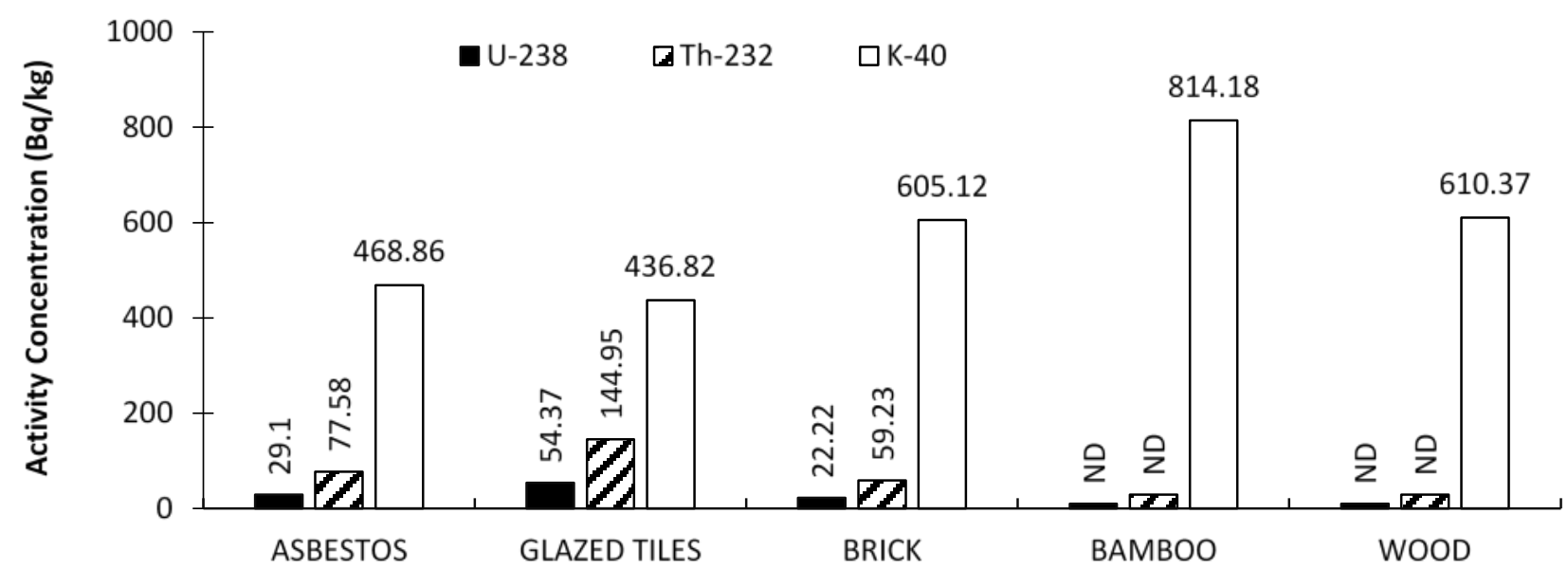

Figure 2: Activity concentration of ${ }^{238} \mathrm{U},{ }^{232} \mathrm{Th} \&{ }^{40} \mathrm{~K}$ in building materials.

Table 1: Activity concentration of ${ }^{238} \mathrm{U},{ }^{232} \mathrm{Th} \&{ }^{40} \mathrm{~K}$ radionuclides in soil samples.

\begin{tabular}{|c|c|c|c|c|c|c|c|}
\hline $\begin{array}{c}\text { Sample } \\
\text { No }\end{array}$ & ${ }^{\mathbf{2 3 8} \mathbf{U}}$ & ${ }^{\mathbf{2 3 2}} \mathbf{T h}$ & ${ }^{\mathbf{4 0}} \mathbf{K}$ & $\begin{array}{c}\text { Sample } \\
\mathbf{N o}\end{array}$ & ${ }^{\mathbf{2 3 8} \mathbf{U}}$ & ${ }^{\mathbf{2 3 2} \mathbf{T h}}$ & ${ }^{\mathbf{4 0} \mathbf{K}}$ \\
\hline 1 & 39.91 & 73.65 & 861.24 & 14 & 37.06 & 71.16 & 987.29 \\
\hline 2 & 19.32 & 57.71 & 1008.37 & 15 & 29.68 & 68.69 & 706.92 \\
\hline 3 & 22.76 & 43.63 & 742.04 & 16 & 22.07 & 60.37 & 1062.73 \\
\hline 4 & 43.68 & 79.57 & 686.58 & 17 & 47.69 & 68.57 & 1119.82 \\
\hline 5 & 21.39 & 73.85 & 1150.81 & 18 & 22.63 & 58.34 & 940.74 \\
\hline 6 & 28.03 & 58.25 & 964.17 & 19 & 44.65 & 75.45 & 975.75 \\
\hline 7 & 24.50 & 58.12 & 1020.85 & 20 & 41.79 & 65.34 & 1068.25 \\
\hline 8 & 47.69 & 68.57 & 1119.82 & 21 & 31.76 & 61.58 & 863.02 \\
\hline 9 & 22.63 & 58.34 & 940.74 & 22 & 41.22 & 85.61 & 836.68 \\
\hline 10 & 44.65 & 75.45 & 975.75 & 23 & 37.06 & 71.16 & 987.29 \\
\hline 11 & 41.79 & 65.34 & 1068.25 & 24 & 29.68 & 68.69 & 706.92 \\
\hline 12 & 31.76 & 61.58 & 863.02 & 25 & 22.07 & 60.37 & 1062.73 \\
\hline 13 & 41.22 & 85.61 & 836.68 & & & & \\
\hline
\end{tabular}


Table 2: Activity concentration of ${ }^{238} \mathrm{U},{ }^{232} \mathrm{Th} \&{ }^{40} \mathrm{~K}$ radionuclides in building materials.

\begin{tabular}{|c|c|c|c|c|c|}
\hline & Asbestos & Glazed Tile & Brick & Bamboo & Wood \\
\hline${ }^{238} \mathbf{U}$ & 29.1 & 54.37 & 22.22 & ND $^{+}$ & ND $^{+}$ \\
\hline${ }^{\mathbf{2 3 2}} \mathbf{T h}$ & 77.58 & 144.95 & 59.23 & $\mathrm{ND}^{+}$ & $\mathrm{ND}^{+}$ \\
\hline${ }^{\mathbf{4 0}} \mathbf{K}$ & 468.86 & 436.82 & 605.12 & 814.18 & 610.37 \\
\hline
\end{tabular}

boo and wood lies in a range to other data as mentioned earlier. From the result of analysis of building materials (Table 2), we can find that bamboo have the highest activity concentration of ${ }^{40} \mathrm{~K}$ and glazed tiles have highest activity concentration of ${ }^{238} \mathrm{U}$ and ${ }^{232} \mathrm{Th}$. The natural sources like wood and bamboo are expected to have more concentration of ${ }^{40} \mathrm{~K}$. The activity concentration of primordial radionuclides in all the samples are lower than the critical value describes by the International Atomic Energy Agency (IAEA) which is $10,000 \mathrm{~Bq} / \mathrm{kg}$ for ${ }^{40} \mathrm{~K}, 1000 \mathrm{~Bq} / \mathrm{kg}$ for all other natural radionuclides (IAEA, 2004).

\section{ACKNOWLEDGEMENT}

The authors are grateful to Radiological Physics and Advisory Division, Bhabha Atomic Research Center, Mumbai, for providing necessary equipment, and the entire residents in the study area who have helped in carrying out this study.

\section{REFERENCES}

Degerlier, M., Karahan, G. and Ozger, G. (2008). Radioactivity concentrations and dose assessment for soil samples around Adana, Turkey. J. Environ. Radioact. 99, 1018-1025.

Haquin, G. (2008). Natural Radioactivity and Radon in Building Materials. $12^{\text {th }}$ International Congress of the International Radiation Protection Association, Buenos Aires.
IAEA (2004). Application of the concepts of exclusion, exemption and clearance, Safety standards series No. RS-G-1.7; 2004.

International Standard, ISO 18589-3:2007(E), 7.3.1 Energy calibration.

Karahan, G., Bayulken, A. (2000). Assessment of gamma dose rates around Istanbul (Turkey). J. Environ. Radioact. 47, 213-221.

Kannan, V., Rajan, M.P., lyengar, M.A.R., Ramesh, R, (2002). Distribution of natural and anthropogenic radionuclides in soil and beach sand samples of Kalpakkam (India) using HPGe gamma ray spectrometry. Appl. Radiat. Isot., 57, 109-119.

Lee, S.C., Kim, C.K., Lee, D.M., Kang H.D., (2001). Natural radionuclides contents and radon exhalation rates in building materials used in South Korea. Radiat. Prot. Dosi., 94(3), 269-274.

Rani, A., Singh, S. (2005). Natural radioactivity levels in soil samples from some areas of Himachal Pradesh, India using $\gamma$ - ray spectrometry. Atmos. Environ. 39, 6306-1634.

UNSCEAR (2000). Annexure B. Exposures from natural radiation, Report to the General Assembly with Scientific Annexes. United Nations, pp. 97-105.

UNSCEAR (2008). Vol I, Annexure B. Exposure to the public and workers from various sources of radiation. Report to the General Assembly. New York, United Nations, p. 234. 